\title{
Intervenções significativas no ensino-aprendizagem da ortografia
}

\author{
Loremi Loregian-Penkal $^{1}$ \\ Cristiane Malinoski Pianaro Angelo²
}

\section{Resumo}

A escola, em geral, exige do aluno uma escrita de acordo com as normas ortográficas, mas oferece poucas oportunidades para pensar com ele acerca das regras de uso da ortografia. Sendo assim, é de vital importância buscar alternativas metodológicas para o ensino construtivo da ortografia, isto é, aquele em que o aluno, engajado em atitude reflexiva, promove processos de descoberta. Neste artigo, propomos uma reflexão a respeito do ensino-aprendizagem da convenção ortográfica proposto no Ensino Fundamental de uma escola da rede pública de Irati-PR. Para tanto, analisamos propostas desenvolvidas com alunos de $5^{\mathrm{a}}$ série, que apresentam dificuldades na disciplina de Língua Portuguesa, e selecionamos algumas atividades referentes à ortografia, objetivando discutir se essas são alternativas viáveis para promover o domínio da convenção ortográfica. Como contribuição, apontamos possíveis reformulações às atividades e sugerimos outras práticas que possam diminuir as dificuldades dos aprendizes.

Palavras-chave: Escrita. Ortografia. Ensino Fundamental.

\begin{abstract}
In general, school demands from the student to write according to the orthographic system, but it offers few opportunities to think with the learner about the rules of using the orthography. Thus, it is essential to search for methodological alternatives for a constructive teaching of the orthography, i.e. that one where the pupil, engaged in reflexive attitude, finds new processes of learning. This article considers a reflection about the teaching/learning of the orthographic convention, applied in a State school of Basic Education in the city of Irati, State of Paraná, Brazil. Therefore, we analyze the proposals developed with the students of the fifth grade who show difficulties in the Portuguese Language orthography. For that reason, we selected some activities that refer to the orthographic system. The objective is to consider if they are suitable alternatives to promote the domain of the orthographic convention. As contribution, we pointed possible reformulations of the activities and we recommended other practices that may reduce the difficulties of the learners.
\end{abstract}

Key-words: Writing. Orthography. Basic Education.

\footnotetext{
${ }^{1}$ Doutorado em Lingüística pela Universidade Federal do Paraná, Brasil(2004). Professor Adjunto D da Universidade Estadual do Centro Oeste , Brasil. E-mail: loremi.loregian@gmail.com

${ }^{2}$ Mestrado em Letras pela Universidade Estadual de Maringá, Brasil(2005). Professor da Universidade Estadual do Centro-Oeste , Brasil.
} 


\section{Considerações iniciais}

Neste artigo, propomos uma reflexão a respeito do ensino-aprendizagem da convenção ortográfica no Ensino Fundamental. Para tanto, analisamos atividades referentes à ortografia, propostas a alunos de $5^{\mathrm{a}}$ série de uma escola da rede pública de Irati-PR que apresentam dificuldades na disciplina de Língua Portuguesa, objetivando discutir se essas são alternativas viáveis para promover o domínio da convenção ortográfica. Como contribuição, apontamos possíveis reformulações às atividades e sugerimos outras práticas que possam diminuir as dificuldades dos aprendizes.

Para atingir o objetivo proposto, estruturamos o artigo da seguinte forma: num primeiro momento, revisamos alguns pressupostos teóricos que orientam o trabalho com a ortografia, para compreender, de fato, qual seria o tipo de intervenção adequada para minimizar as dificuldades apontadas. Em seguida, avaliamos algumas atividades que foram desenvolvidas em sala de aula, com alunos da $5^{\text {a }}$ série do Ensino Fundamental, demonstrando aquelas que se constituem em intervenções significativas, bem como apontando possíveis inadequações nas propostas e sugerindo outros encaminhamentos que podem alicerçar o trabalho do professor em sala de aula.

Acreditamos que a reflexão, aqui apresentada, poderá trazer contribuições ao ensino da ortografia em sala de aula, algumas vezes negligenciado, outras vezes tomado como meio para punir ou ameaçar o aluno.

\section{Alfabetização e ortografia}

A escrita ortográfica, tradicionalmente, e principalmente na escola, é encarada como algo resultante de um esforço de memorização e obtida à custa de repetição. Segundo Nunes (1988, p. 6), o ensino da ortografia deve ser feito através de treinamento e "de acordo com o princípio fundamental da aquisição da ortografia: repetição atenta da escrita de palavras”, pois “é sabido que os hábitos se formam através da repetição das ações”. Além disso, “a boa pronúncia das palavras tem influência direta sobre seu registro gráfico. Muitos erros, bastante comuns, deverão ser corrigidos previamente na linguagem oral”.

Tal proposta pedagógica baseia-se em uma sequência de sessões de treinos ortográficos em que "cada palavra deve ser repetida [por escrito] de duas a cinco vezes, ... não 
sendo conveniente repeti-la mais de cinco vezes na mesma sessão”, sendo que "o resultado obtido com o treinamento de palavras isoladas é superior ao de palavras na frase”. O treinamento, segundo a autora, deve seguir uma escala cujas dificuldades vão sendo acrescentadas: “limitar, na primeira série, o treino de palavras com mais de duas sílabas”; utilizar inicialmente palavras compostas de sílabas formadas por apenas uma vogal e uma consoante; depois disso passar a treinar palavras com "h"; a seguir palavras com "sc"; etc.

Para Fagundes (1988, p. 17), a aquisição da ortografia ocorre “através da memorização da forma e dos movimentos para escrever as palavras”, sendo que esse objetivo é atingido por meio de exercícios repetitivos e treinamento para "fixar e conservar a imagem motora de palavras”.

Como podemos perceber, a concepção de desenvolvimento do conhecimento, empregada por essas autoras, não é algo que seja específico para o ensino da língua escrita e da ortografia, sendo frequentemente empregada para o ensino de qualquer conteúdo escolar.

Quanto ao aspecto de se ensinar primeiramente a pronúncia correta para posteriormente se trabalhar as questões ortográficas, percebemos que esta visão é bastante comum nos meios escolares. Mas alguns autores se posicionam frontalmente contrários a essa proposta, argumentando a respeito da diferenciação entre língua falada e língua escrita.

Desde a perspectiva psicolinguística, Kato (1986) nos alerta que, embora a escrita alfabética (representação de segunda ordem) tenha sido concebida para representar a fala (representação de primeira ordem), ela não chega a ser uma escrita fonética. As modalidades oral e escrita da linguagem apresentam uma isomorfia apenas parcial, porque fazem a seleção a partir do mesmo sistema gramatical e podem expressar as mesmas intenções. O que determina as diferenças entre elas são as diferentes condições de produção, tais como: a dependência contextual, o grau de planejamento, a submissão consciente às regras prescritivas convencionalizadas para a escrita.

Por sua vez, dirigindo-se aos professores alfabetizadores, Lemle (1987, p. 27) trata de deixar claro que, ao contrário do que supõe o alfabetizando, “é bastante complicada a relação dos sons da fala com as letras”. Do ponto de vista do aluno, que está aprendendo a ler e a escrever, "apropriar-se da ideia de que existe uma correspondência biunívoca entre sons e letras é fundamental”, mas ele logo terá que relativizar a concepção de que para cada letra existe apenas um som e de que para cada som existe apenas uma letra.

Lemle ataca a noção de que as crianças que não escrevem ortograficamente assim o fazem porque falam errado: “dizer que alguém fala errado corresponde a um equívoco linguístico, um desrespeito humano e um erro político”. Um equívoco linguístico, pois ignora 
o fato de que as diferentes comunidades linguísticas possuem os seus próprios dialetos. Um desrespeito humano, pois humilha e desvaloriza a pessoa que recebe a qualificação de que fala errado. Um erro político, pois ao se rebaixar a autoestima linguística de uma pessoa ou de uma comunidade, contribui-se para achatá-la, amedrontá-la e torná-la passiva, inerte e incapaz de manifestar seus anseios.

Cagliari é outro linguista que afirma que a linguagem é dinâmica, modificando-se em função do tempo e do espaço, não podendo ser consideradas como erradas as falas características de uma dada comunidade. O autor salienta também as diferenças entre língua escrita e falada:

A fala tem aspectos (contextuais e pragmáticos) que a escrita não revela, e a escrita tem aspectos que a linguagem oral não usa. São dois usos diferentes, cada qual com suas características próprias, sua vida própria, almejando finalidades específicas (1997, p. 37).

A aparente arbitrariedade da ortografia possui uma regularidade nem sempre compreendida: a função de representar mediante constantes gráficas os conteúdos semanticamente relacionados. O sistema ortográfico não possui uma correspondência estrita com o sistema fonológico e, consequentemente, deve recorrer a representações gráficas que permitam reconhecer as relações morfosintáticas no texto escrito.

\section{Questões fundamentais para o ensino da ortografia: O que é? Para que serve? Por que ensinar? Como ensinar ortografia?}

Conforme apontam os estudos sociolinguísticos, a variação é uma qualidade constitutiva do fenômeno linguístico. Encontramos, assim, realizações diferentes entre falantes de origem geográfica, classe social, sexo, idade e nível de escolaridade distintos. Por exemplo, em determinadas regiões, costuma-se falar "leitchi quentchi”, em outras, "leiti quenti” e em outras regiões, ainda, podemos ouvir "leite quente”. Entre falantes de alto nível de escolaridade, encontramos realizações como "globo", "bloco”, enquanto que entre falantes de baixa escolarização podemos ouvir “grobo”, “broco”.

Sabemos que todo usuário de uma língua varia sua fala de acordo com a situação em que se encontra. Desse modo, numa situação mais formal (como a apresentação de um seminário) é provável que o falante produza, por exemplo, você; espera aí; está bem? Já em 
uma situação mais informal (conversa numa roda de amigos, numa lanchonete), o falante provavelmente produzirá cê; pera aí; tá bem?

Essas diferenciações são constatadas na modalidade oral da linguagem, pois, na escrita, existe a ortografia, isto é, um recurso que “congela” as várias maneiras de falar dos usuários da mesma língua, ou como definiu Morais (2005, p. 8), “um tipo de saber resultante de uma convenção, de negociação social e que assume caráter normatizador, prescritivo”.

Durante muito tempo, a correção ortográfica foi cobrada drasticamente e de maneira mecânica na sala de aula. Atividades como identificação de erros dos alunos nos textos, cópia exaustivamente repetida dos erros cometidos, ditados com correção das grafias das palavras e exercícios de preenchimento de lacunas faziam parte da rotina das aulas de português.

Assim, para dirimir a mecanicidade, o trabalho com a normatização ortográfica precisa estar contextualizado, basicamente, em situações em que "os alunos tenham razões para escrever corretamente", em que a legibilidade seja fundamental porque existem leitores de fato para a escrita que produzem. Deve estar voltado para o desenvolvimento de uma atitude crítica em relação à própria escrita, ou seja, de preocupação com a adequação e correção dos textos. No entanto, diferentemente de outros aspectos da notação escrita - como a pontuação -, “as restrições da norma ortográfica estão definidas basicamente no nível da palavra”. Isso faz com que o ensino da ortografia possa desenvolver-se por meio, tanto de atividades que tenham "o texto como fonte de reflexão como de atividades que tenham palavras não necessariamente vinculadas a um texto específico" (BRASIL, 1997, p. 36). Nos últimos anos, as amplas discussões a respeito das práticas de ensino da língua culminaram na redefinição dos objetivos do ensino da língua portuguesa na escola. Agora, pensa-se não mais em "treinar" os alunos para que escrevam corretamente, mas em constituir usuários competentes da língua materna. Por isso, o texto passou a ser o cerne do processo de ensino e aprendizagem, visto que a leitura e a produção de textos começaram a ser consideradas como atividades fundamentais no processo de integração social.

Desde então, surgiu um outro extremismo, na prática escolar, em oposição ao modelo tradicional que não priorizava a formação de alunos leitores e produtores de textos. Alguns professores passaram a adotar uma atitude de menosprezo para com o ensino da ortografia. Outros, ainda, numa ação totalmente arbitrária, deixaram de intervir no processo de ensinoaprendizagem, em uma atitude de não dar atenção à correta notação da escrita, mas continuaram a cobrar e a punir os erros dos alunos, "tirando" nota daqueles que não escrevessem em conformidade com as normas ortográficas (MORAIS, 2001). 
Nossa intenção, neste texto, é expor um repensar acerca dessa atitude mecanicista e propor um ensino que trate a ortografia como objeto de investigação. Nesse sentido, assumimos uma postura favorável ao trabalho com a convenção ortográfica em sala de aula, por duas razões: primeiro, se a ortografia “congela” na escrita as diferenças no modo de falar dos usuários de uma mesma língua, esse recurso faz com que “as variações linguísticas da fala não atrapalhem a tarefa do resgate do significado textual”, facilitando a comunicação escrita; segundo, os erros de ortografia "funcionam como uma fonte de censura e de discriminação, tanto na escola como fora dela” (MORAIS, 2001, p. 18). Nesse sentido, “ao negligenciar sua tarefa de ensinar ortografia, a escola contribui para a manutenção das diferenças sociais, já que ajuda a preservar a distinção entre bons e maus usuários da língua” (MORAIS, 2001, p. 24).

Para um ensino produtivo da ortografia, torna-se fundamental verificar, como ponto de partida, que tipos de erros ortográficos os alunos cometem em seus textos, isto é, se os desvios correspondem a uma dificuldade irregular ou regular (MORAIS, 2001).

De irregular denominam-se as grafias que se justificam pela tradição de uso, ou pela etimologia, como o 'c' da palavra cidade, que o aluno pode vir a escrever com 'c' ou 's'. Para este caso, não existe uma regra que possa justificar a escrita de uma maneira e não de outra. Resta ao aprendiz memorizá-la, ou seja, conservar na mente a imagem visual da palavra.

No caso das dificuldades regulares, é possível prever a forma correta sem nunca ter visto a palavra antes. Infere-se a forma correta porque existe um princípio gerativo, uma regra que se aplica a várias palavras da língua nas quais aparece a dificuldade em questão.

Fazer a distinção entre o que é regular e o que é irregular em nossa ortografia é essencial para o professor definir as suas ações. Isso porque os erros têm causas diversas, portanto, há necessidade de estratégias distintas para superá-los. Ainda, entre os casos de regularidades, podemos identificar três tipos: regulares diretas, regulares contextuais e regulares morfológico-gramaticais.

O primeiro grupo inclui a grafia dos chamados “pares mínimos”: p/b, t/d e f/v, em que há uma só letra para cada som. Muitos aprendizes podem confundir na hora de registrar algumas palavras, escrevendo "parco", por exemplo, ao invés de "barco”. Isso se deve ao fato de os sons em questão serem muito similares em sua realização no aparelho fonador, ou seja, são produzidos expelindo-se o ar do mesmo modo e lugar de articulação, diferenciando-se apenas porque um (por exemplo, o /b/) é vozeado - ocorre vibração nas cordas vocais - e o outro (/p/) é desvozeado - não ocorre vibração. 
Regulares contextuais são casos em que a posição, dentro da palavra, vai determinar a letra a ser usada. O caso do 'r' e do 'rr' constitui um bom exemplo. O som /R/ aparece tanto no início da palavra como no meio de vogais, mas em começo de palavras devemos usar apenas um ' $r$ ', enquanto entre vogais, temos de usar 'rr'. O uso do ' $z$ ' inicial é outro exemplo. Sabemos que o som / $z$ / pode ser representado pelo grafemas ' $z$ ', 's' e ' $x$ ', no entanto, no início de palavras, sempre usamos ' $z$ '.

Regulares morfológico-gramaticais são casos em que é a categoria gramatical da palavra que estabelece a regra. Por exemplo, “macaquice”, “chatice” e outros substantivos terminados com o sufixo “ice” se escrevem sempre com 'c'; já as formas do pretérito imperfeito do subjuntivo - $3^{\text {a }}$ conjugação - são escritas com 'ss': “partisse”, “ouvisse”, saísse.

O conhecimento das regras contextuais e morfológico-gramaticais permite ao aluno compreender e usar os princípios gerativos, que lhe possibilitarão resolver uma série de problemas na escrita, sem precisar armazenar formas ortográficas na memória.

\section{Análise de atividades específicas para o domínio da ortografia}

A partir deste momento, apresentaremos e teceremos comentários acerca de algumas atividades, referentes à ortografia, propostas a alunos de $5^{\mathrm{a}}$ série do Ensino Fundamental, da rede pública de Irati-PR, objetivando discutir se essas são alternativas viáveis para promover o domínio da convenção ortográfica. Como contribuição, apontaremos possíveis reformulações para as atividades e sugeriremos outras práticas que possam sanar as dificuldades dos aprendizes.

Torna-se importante destacar o fato de alunos de $5^{\mathrm{a}}$ série ainda não dominarem, lamentavelmente, princípios ortográficos básicos. Acreditamos que esse problema seja, em parte, motivado pela ausência de atividades sistemáticas de ensino e aprendizagem de ortografia, bem como pelo uso de metodologias inadequadas, como a de solicitar a produção de textos sem que os mesmos passem por uma correção e respectiva refacção dos erros apontados para que o aluno possa ser estimulado a revisar o que produz e possa, dessa forma, autocorrigir-se.

No entanto, embora necessárias, tais atividades não podem se tornar excessivas e tampouco desinteressantes e desestimulantes ao aluno. Caso contrário, incorre-se na destruição do discurso do aluno, como bem aponta Cagliari: 
O controle das formas ortográficas é conveniente para fazer avaliações de massa nas classes, mas um desastre para ensinar alguém a escrever o que pensa. O excesso de preocupação com a ortografia desvia a atenção do aluno, destruindo o discurso linguístico, o texto, para se concentrar no aspecto mais secundário e menos interessante da atividade de escrita. Além disso, o controle ortográfico destrói o estímulo que a produção de um texto desperta numa criança (1997, p. 124).

\section{Atividade 1:}

Complete as palavras com 't' ou 'd' e encontre-as no quadro abaixo:

$$
\begin{aligned}
& \text { sabone....e } \\
& \text { ca....ea....o } \\
& \text { arma....ura } \\
& \text { fu....ebol } \\
& \text { cor....a }
\end{aligned}
$$

(Obs.: na atividade proposta, constava, ainda, um caça-palavras com as palavras listadas anteriormente)
...eimosa
coca....a
serro....e
gela...o
gra....e

\section{Atividade 2:}

Troque o 't' pelo 'd' e forme novas palavras

$\begin{array}{ll}\text { teto } & \text { tom } \\ \text { tia } & \text { gato } \\ \text { tato } & \text { nada } \\ \text { tela } & \text { vendo } \\ \text { teus } & \text { data }\end{array}$

Vê-se que os exercícios propostos nas atividades 1 e 2 buscam suprir uma dificuldade referente a uma propriedade regular direta: a troca entre t e d. Embora nessa propriedade haja uma regularidade entre som e letra, o aluno pode realizar tal troca porque tem alguma dificuldade em analisar fonologicamente os segmentos sonoros na hora em que está escrevendo.

No que se refere à atividade 2, o aluno pode perceber que a troca de uma letra por outra gera uma nova palavra com uma significação completamente distinta da que possuía anteriormente. Saliente-se, entretanto, que a atividade só poderá render bons resultados se 
duas condições forem atendidas: primeiro, a questão ortográfica precisa tornar-se objeto de reflexão, ou seja, o professor precisa refletir com o aluno sobre o que acontece caso realizemos as trocas, neste caso o " $\mathrm{t”}$ " pelo “d”, pois do contrário, o exercício consistirá numa prática mecânica que em nada renderá ao aluno; segundo, no enunciado da atividade 2, há um problema de “comando” que precisa ser revisto, pois é solicitado que o aluno faça somente a troca do " $t$ " pelo “ $d$ " e, no rol de palavras elencadas, as palavras “nada” e "vendo" não se encaixam no comando proposto. Esse problema pode reforçar ainda mais a dificuldade do aluno e a "confusão” ortográfica.

Com relação à atividade 1, sugerimos que, após preencher as lacunas, o aprendiz classifique-as em dois conjuntos. Feita a separação, os alunos leem o que colocaram em cada coluna e discutem com o professor se há algo "fora do lugar”. Em seguida, solicita-se a eles que produzam outras palavras que possam ficar na mesma coluna.

Também, sugerimos a escrita, leitura e reflexão ortográfica de trava-línguas, como os citados abaixo:

- Alô, o tatu taí?

- Não, o tatu não tá, mas a mulher do tatu tando é o mesmo que o tatu tá.

O doce perguntou pro doce:

- Qual o doce mais doce?

O doce respondeu pro doce que o doce mais doce é o doce de batata-doce.

É um dedo, é um dado, é um dia. É um dia, é um dado, é um dedo.

Três pratos de trigo

Para três tigres tristes

Para o trabalho com outras regulares diretas, há também divertidos trava-línguas que podem ser devidamente explorados em sala, como:

O que é que Cacá quer? Cacá quer caqui. Qual caqui que Cacá quer? Cacá quer qualquer caqui.

Meu pai chama Caco, minha mãe Caca Maria. Ai, meu Deus! Que tanto caco! Eu sou filho da cacaria.

Farofa feita com muita farinha fofa faz uma fofoca feia.

O café está fraco, frio, com formiga no fundo, fazendo fofoca. 
Paulo Pereira Pinto Peixoto, pobre pintor português, pinta perfeitamente, portas, paredes e pias, por parco preço, patrão.

Poder-se-ia, primeiramente, solicitar aos alunos que efetuem a leitura silenciosa dos trava-línguas; em seguida, o professor poderia solicitar e explorar a leitura em voz alta. Com isso, os alunos estariam exercitando e constatando as diferenças na pronúncia dos travalínguas e verificando por que são tão difíceis de pronunciar, principalmente em uma leitura rápida. Pode-se solicitar ainda que, a partir de um determinado trava-língua, o aluno realize a troca de uma letra por outra e reflita se a troca resultou em alguma diferença.

Meu pai chama Caco, minha mãe Caca Maria. Ai, meu Deus! Que tanto caco! Eu sou filho da cacaria.

Meu pai chama Gago, minha mãe Gaga Maria. Ai, meu Deus! Que tanto gago! Eu sou filho da gagaria.

Sugere-se também que, a partir do que foi trabalhado em sala, os alunos pesquisem e produzam uma coletânea de trava-línguas.

\section{Atividade 3:}

Complete as palavras abaixo com $m$ ou $n$

$\begin{array}{ll}\text { ca....pina } & \text { tro....co } \\ \text { ci....tura } & \text { ma....so } \\ \text { ta....borete } & \text { po....ba } \\ \text { vale....te } & \text { i....posto } \\ \text { li....peza } & \text { segu....do } \\ \text { seme....te } & \text { e....brulhar } \\ \text { e....blema } & \text { ca....balhota } \\ \text { mora....go } & \text { pi....tar } \\ \text { pime....ta } & \text { e....baixo } \\ \text { te....pestade } & \text { ma....dioca }\end{array}$




\section{Atividade 4:}

É com l ou u:

carrete....

fi....me

a....mento

minga.... a....godão

a....tomóve....

futebo....

carroce...

Os exercícios propostos para o aluno procuram dar conta de dois casos diferenciados de dificuldades ortográficas: a primeira atividade se refere a uma dificuldade regular contextual e a segunda a uma dificuldade irregular. Embora sejam casos bem diferentes, propôs-se ao aluno um mesmo tipo de atividade: o preenchimento de lacunas.

Nossa opinião, quanto à atividade 3, é que se bem conduzida em sala de aula - isto é, se o professor estimular a reflexão - a mesma pode ser aplicada, uma vez que o contexto da palavra pode auxiliar o aprendiz na resolução da dúvida. Entretanto, acreditamos que se o professor ajudar o aluno a refletir e explicitar a regra para o uso das grafias, a proposta pode se tornar mais significativa. Ilustremos com um exemplo:

a) Transcreva as palavras a seguir, separando as que são escritas com 'm’ (no final da sílaba) das que são escritas com 'n’: branco, brinde, embalar, branco, longe, conta, pomba, lâmpada, fonte, tambor, sempre, campo, imperador

b) Agora, responda:

- Que letras aparecem nas palavras acima, depois de 'm'?

- Que letras aparecem nas palavras acima, depois de 'n'?

- Procure outras palavras que possam ser encaixadas nos conjuntos 1 e 2:

- Agora formule a regra para o uso do 'm' e do 'n':

Acreditamos que essas tarefas predispõem os alunos a engajarem-se em atitude investigativa, testando hipóteses, comparando, concluindo.

Também, a releitura com focalização (Morais, 2001), pode ser uma boa estratégia. Para realizá-la, o professor toma um texto já conhecido, lê com os alunos, fazendo interrupções em algumas dificuldades ortográficas: "por que tal palavra escreve com m e não 
n?” “como uma pessoa que está começando a aprender a escrever, pode errar ao escrever tal palavra? Desse modo, o ensino da ortografia passa a ter um caráter criativo, condizendo com as abordagens atuais que consideram o processo de ensino-aprendizagem como construção.

Já a atividade 4, além de improdutiva, estimula a insegurança; mesmo que o aluno já tenha "fotografado" em sua memória a grafia de algumas palavras não hesitará em perguntar: afinal, é com 'l' ou com 'u'? Por isso, consideramos mais conveniente que o professor elimine de sua prática os exercícios de preenchimento de lacunas que se referem a casos de irregularidades, pois tais exercícios reforçam a dúvida e o medo de errar, já que não existe um princípio gerativo capaz de auxiliar o aluno.

Então, o que fazer para solucionar problemas com irregularidades?

Morais (2001) propõe duas atividades. A primeira é que o professor, a partir da análise das produções escritas dos alunos, levante quais as palavras eles mais frequentemente escrevem "errado" e estabeleça um acordo com a turma, definindo quais palavras eles não poderão mais escrever errado naquela semana. Essas palavras serão transcritas em um cartaz, a ser produzido pelos próprios alunos, e afixado na parede da sala. Duas questões aqui merecem atenção: primeiro, que sejam selecionadas as palavras de uso frequente; segundo, que se esclareça para o aluno que para aquelas palavras não há uma regra específica, por isso é preciso memorizá-las.

A segunda atividade pode ser uma continuação da atividade anterior. Solicita-se ao aluno que escreva outras formas que pertençam à mesma família das palavras selecionadas:

Casar - casamento, casal, casado.

Humano - humanitário, humanidade.

História - historiador, historinha.

Cremos que esse tipo de atividade auxilia o aprendiz a estabelecer analogias e a lançar mão desse recurso em situações em que se fizer necessário.

Lembramos, no entanto, que estamos tratando de irregularidades, isto é, de casos em que a internalização depende da memória visual. Por isso, quanto mais o aprendiz estiver exposto às palavras, mais estas poderão criar “imagens fotográficas” em sua mente. 


\section{Para concluir}

Conforme apontamos ao longo do artigo, uma das tarefas da escola é criar condições para que o aluno construa seu conhecimento de forma investigativa e crítica.

Em relação ao trabalho com a ortografia, cabe à escola favorecer a explicitação dos conhecimentos dos alunos sobre as restrições da norma ortográfica. Além disso, a escola precisa propiciar atividades diversas e criativas nas quais os alunos não respondam as atividades de modo automático ou mecânico.

Para tanto, o aluno precisa ser estimulado a inferir sobre o porquê das notações corretas. Assim, cabe à instituição escolar assumir a responsabilidade de promover uma aprendizagem adequada e explícita dos aspectos inerentes à notação escrita do português, aspectos esses que o indivíduo precisa conhecer para ter êxito em ortografia (MORAIS, 2005).

Por fim, lembramos a necessidade de que se tenha a presença constante, na escola, de atividades sistemáticas de ensino e aprendizagem de ortografia, bem como o uso de metodologias adequadas, como a de solicitar a produção de textos espontâneos aos alunos e que tais textos passem por uma correção e respectiva refacção dos problemas levantados. Dessa forma, o aluno passa a ser estimulado a revisar constantemente o que produz, a refletir acerca das convenções ortográficas e, assim, passa a ter consciência da importância de se autocorrigir e, principalmente, de se colocar no papel de "leitor” de seu próprio texto.

\section{Referências}

BRASIL. Secretaria de Educação Fundamental. Parâmetros Curriculares Nacionais: Terceiro e Quarto Ciclos do Ensino Fundamental: Língua Portuguesa. Brasília: MEC/ SEF, 1998.

CAGLIARI, Luiz Carlos. Alfabetização \& Linguística. São Paulo: Scipione, 1997.

FAGUNDES, Ana Rita. Ortografia na primeira série. Revista Pedagógica, Belo Horizonte, v. 6, n 33, mai/jun 1988.

KATO, Mary. No mundo da escrita: uma perspectiva psicolinguística. São Paulo: Ática, 1986.

LEMLE, Miriam. Guia teórico do alfabetizador. São Paulo: Ática, 1987. 
MORAIS, Artur Gomes de. Ortografia: ensinar e aprender. São Paulo: Ática, 2001.

O aprendizado da ortografia. 3. ed. Belo Horizonte: Autêntica, 2005.

NUNES, Carolina. O ensino da ortografia na escola de primeiro grau. Revista Pedagógica, Belo Horizonte, v. 6, n. 33, mai/jun 1988. 